\title{
Urologic complications of HIV and AIDS
}

\section{Chris F Heyns,}

University of Stellenbosch, Department of Urology, Faculty of Health Sciences, PO Box 19063, Tygerberg 7505, South Africa

\section{Adam E Groeneveld}

Urologist in Mbabane, Swaziland

\section{Nelson B Sigarroa}

Professor in Urology at the Walter Sisulu University (formerly the University of the Transkei), Mthatha, Eastern Cape, South Africa

\section{SUMMARY}

In recent years the nature of HIV infection has been dramatically transformed from an invariably fatal disease to a chronic disorder with a relatively benign course. Disease progression from HIV to AIDS and HIV-related mortality can be reduced effectively by several years of treatment with highly active antiretroviral therapy (HAART). For patients who do not have access to HAART, HIV infection continues to be a lethal disorder characterized by opportunistic infection with uncommon organisms (e.g. mycobacteria, fungi, parasites and viruses), as well as lethal malignancies such as Kaposi sarcoma, non-Hodgkin lymphoma and squamous cell carcinoma of the penis or cervix. In patients receiving HAART, urologic complications are likely to be caused by adverse effects of antiretroviral medication (e.g. indinavir urolithiasis) or disorders associated with aging, such as benign prostatic hyperplasia and prostate cancer. Prospective clinical trials have shown that adult male circumcision can reduce the rate of female to male HIV transmission by more than $50 \%$; however, the development of preventive or curative modalities with $100 \%$ efficacy remains elusive.

\section{REVIEW CRITERIA}

A comprehensive PubMed search of the English-language literature published between January 1980 and March 2008 was made for relevant articles using the Medical Subject Heading terms "HIV", "AIDS" and "urology" or "urological(al)" in various combinations. The reference lists of retrieved articles were assessed for additional articles.

Keywords: AIDS, HIV, urologic complications

\section{INTRODUCTION}

HIV is a retrovirus that replicates rapidly and kills helper T cells, which are the body's main cellular defense against infection. HIV is spread through contact with blood, semen and vaginal secretionsfor example during homosexual or heterosexual intercourse, by use of contaminated needles or blood products, or from mother to child during birth or through breast feeding.

AIDS refers to the disorder caused by HIV infection. AIDS usually occurs when $\mathrm{CD} 4^{+}$count falls below 200 cells $/ \mathrm{mm}^{3}$. The clinical course of the disease is characterized by recurrent infection by various uncommon opportunistic bacteria, fungi and viruses, which can involve any part of the urogenital system. Despite the aggressive nature of standard therapy, AIDS can have a rapidly fatal course in most patients.

In the past decade, the increasing availability of antiretroviral drugs has helped combat HIV replication and has changed HIV infection from an almost invariably fatal disorder to just another chronic illness. HIV-positive patients who are treated with highly active antiretroviral therapy (HAART) have an almost normal life expectancy, and are now presenting with common urologic disorders that usually affect elderly people. Unfortunately, HAART is not readily available in many of the countries that have the highest prevalence of HIV infection-in these regions AIDS has retained its profile as a severely debilitating and eventually fatal disorder. 
Urologic disorders (Box 1 ) are often the first clinical signs that indicate possible HIV infection. In this Review we discuss the main urologic complications in patients with HIV and AIDS, including complications resulting from treatment.

\section{EPIDEMIOLOGY OF HIV AND AIDS}

WHO data show that the global prevalence of HIV infection has leveled off-39.5 million people were affected in 2006 and 33.2 million in 2007. Worldwide, 2.5 million people became newly infected in 2007, and 2.1 million died of AIDS. ${ }^{1}$ Although the incidence of new cases has leveled off, the total number of people living with HIV infection is increasing.

Sub-Saharan Africa contains $10 \%$ of the world's population but accounts for less than $1 \%$ of the world's health expenditure. This region bears more than $70 \%$ of the global burden of HIV and AIDS, with an estimated 22.5 million people living with HIV. ${ }^{2}$ It is expected that the AIDS death toll in subSaharan Africa will continue to rise due to inadequate prevention and reduced treatment efforts compared with other parts of the world; therefore, a substantial increase in the magnitude of the AIDS epidemic is expected during the course of the next 10 years. $\frac{3}{-}$

In 2007, HIV incidence in Eastern Europe and Central Asia increased by more than $150 \%$. In Vietnam HIV incidence more than doubled between 2000 and 2005, and Indonesia has the fastest growing epidemic. ${ }^{4}$ The prevalence of HIV continues to increase in the US, which currently has an estimated 1.2 million people living with HIV; about $74 \%$ of cases are in adult men, and the epidemic continues to disproportionately affect African Americans. $.5,6$

\section{UROLOGIC COMPLICATIONS OF HIV AND AIDS}

\section{RENAL DYSFUNCTION}

Acute renal failure in HIV-infected patients is common and is associated with advanced immunodeficiency. ${ }^{?}$ Kidney disease and subsequent renal failure is the fourth leading cause of death in HIV-positive patients. ${ }^{8}$ Renal dysfunction in patients with HIV can be caused by nephrotoxic medications such as antibiotics and antifungals, metabolic dysfunction and volume depletion as a result of chronic diarrhea, ureteral obstruction from malignancy, infections, and intrinsic diseases such as HIV-associated nephropathy (HIVAN), which occurs in $10-30 \%$ of patients with HIV.

One-year mortality in patients with HIVAN is $50 \%$; even in those being treated with HAART it is approximately $30 \% . \stackrel{-}{-}$ HIVAN is characterized by acute decline in kidney function, high-grade proteinuria (more than $3.5 \mathrm{~g}$ of protein excreted per day), edema, hypertension and anemia, and is associated with $\mathrm{CD}^{+}$counts $<350$ cells $/ \mathrm{mm}^{3}$. Renal ultrasound usually shows that the kidneys are of normal size but have increased echogenicity. Diagnosis of HIVAN is confirmed with renal biopsy. Histologic findings include focal segmental glomerulosclerosis, usually with tubulointerstitial nephritis. 9

In a single study from South Africa, $\underline{\underline{10}}$ renal biopsies in HIV-positive black patients showed that the main histologic categories of kidney disease were classic HIVAN (27\%) and HIV-related 'immune complex kidney disease' (21\%). Other glomerulonephritides included membranous disease, postinfectious disease, mesangial hyperplasia, and immunoglobulin A nephropathy. Overlapping clinical presentations prevented prebiopsy histologic predictions. $\frac{10}{}$ Treatment of HIVAN includes HAART, corticosteroids, angiotensin-converting-enzyme inhibitors, and, eventually, renal replacement therapy. $\underline{.11,12}$ 
Ureteral obstruction can be caused by Burkitt lymphoma that directly involves the ureter $\underline{\underline{13}}$ or by lymph-node metastases of other malignancies such as Kaposi sarcoma or testis tumors. Patients with ureteral obstruction might require ureteral stenting or percutaneous nephrostomy. The incidence of renal involvement in patients with non-Hodgkin lymphoma who have AIDS is $6-12 \%$, and presentation can be bilateral. $\underline{14,15}$

Although patients with HIV are usually excluded from dialysis and renal transplantation, there are now several reports in the literature of successful renal transplantation in HIV-positive recipients on HAART. Gruber and colleagues $\frac{16}{6}$ reported acute rejection rates between $43 \%$ and $67 \%$ in patients with renal transplants and HIV, and patient and graft survivals of $100 \%$ and $88 \%$, respectively.

\section{URINARY TRACT INFECTION}

A study in the 1980 s reported a $17 \%$ incidence of urinary tract infections (UTIS) in HIV-positive patients, $\underline{17}$ but a study in 2003 showed that $38 \%$ of patients with HIV had a bacterial infection

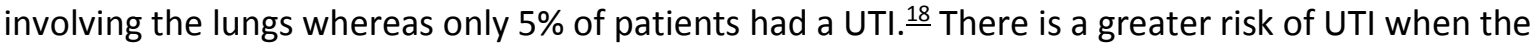
$\mathrm{CD}^{+}$count falls below 500 cells $/ \mathrm{mm}^{3} . \underline{19,20}$

The most common bacterial cause of UTIs in patients with HIV is Enterococcus faecalis. $\stackrel{21}{ }$ Other pathogens that can cause UTIs in patients with HIV areEscherichia coli, Staphylococcus aureus, Klebsiella pneumoniae, Pseudomonas aeruginosa, Acinetobacter spp., Proteus spp., Staphylococcus epidermidis, group D streptococci, Serratia spp. and Salmonella spp. $\frac{14,15,17,20,22}{}$ Pathogens in the urine of HIV-infected patients have shown high antimicrobial resistance. $\underline{23}$

Atypical pathogens that have the capacity to cause a UTI in patients with HIV include fungi (Candida albicans, Aspergillus fumigatus, Blastomyces spp.,Cryptococcus neoformans, Cryptosporidium spp. and Histoplasma capsulatum), parasites (Toxoplasma gondii and Pneumocystis carinii),Mycobacterium spp. (Mycobacterium tuberculosis and Mycobacterium aviumcomplex) and viruses (cytomegalovirus and adenovirus). $\underline{24,25,26}$

In patients with AIDS and reported renal abscesses, satisfactory results have been achieved with only antibiotics and HAART. Percutaneous drainage of renal abscesses and appropriate cultures of aspirated pus are important to diagnose opportunistic infections. Nephrectomy is indicated when conservative therapy fails or septic shock supervenes..$\underline{27}$

Nosocomial infections are common in patients with HIV because central venous catheters and urinary catheters are often used in this patient population. Bloodstream infections are the most common nosocomial infection, followed by UTIs, vascular infections, and pneumonia. HIV-positive patients are more likely to have nosocomial infections caused by $S$. aureus than by any other pathogen. $\underline{28}$

\section{BLADDER DYSFUNCTION}

Voiding disorders are usually caused by infection (e.g. cystitis or prostatitis), obstruction (e.g. of the bladder neck or urethra) or neurologic disorders (e.g. encephalitis, myelitis or acute idiopathic polyneuritis). Several unusual disorders can also cause neurogenic bladder dysfunction, such as herpetic ascending myelitis, cerebral toxoplasmosis and HIV encephalitis. $\underline{29,30}$

Bladder outlet obstruction caused by prostatic enlargement accounts for less than $20 \%$ of cases of urinary retention in HIV-positive patients. $\frac{29,30,31}{}$ As HIV survival and the mean age of patients on HAART increases, however, there will be an increased incidence of symptoms and complications due to benign prostatic hyperplasia. 
Patients with AIDS are also at risk of developing non-Hodgkin lymphoma or rare infections of the bladder by T. gondii; cystoscopic bladder biopsies are needed to make the diagnosis. $\underline{32}$

\section{TUBERCULOSIS}

The incidence of tuberculosis has tripled during the past two decades in countries with a high prevalence of HIV. $\frac{33}{-}$ About a third of people living with HIV worldwide are infected with tuberculosis. Patients who are HIV positive and are not infected with tuberculosis have a 10-15\% risk of developing the infection. $\underline{33}$ Tuberculosis has become the leading cause of death among HIV-positive patients in Africa and is the most common presenting illness among people with HIV who are taking HAART. $\underline{34}$ In many developing countries, concurrent HIV and tuberculosis epidemics have considerably affected already poor public health services.

Active tuberculosis might be associated with a high HIV viral load, low $\mathrm{CD} 4^{+}$counts and rapid progression of HIV infection to AIDS. $\frac{35}{-}$ In patients who are immunocompromised, tuberculosis will usually manifest as a severe systemic infection with bacteremia, disseminated lesions and multiple parenchymatous renal foci. $\frac{36}{}$

Patients with AIDS who have urogenital tuberculosis (UGTB) tend to be younger than HIV-negative patients with UGTB (median age 26 years vs 35 years). Patients with AIDS and UGTB usually have fever, a high probability of parenchymatous renal involvement and disseminated tuberculosis, a low prevalence of storage symptoms and stenosis of the collecting system, and contracted bladder (Figure 1). In addition, the disease course is usually shorter in patients with AIDS who have UGTB than in patients with only UGTB. In patients with AIDS, UGTB often has systemic symptoms, multiple parenchymatous renal foci, and a low frequency of lesions of the collecting system, and can develop into disseminated TB. $\underline{33}$

Drug treatment is the first-line strategy in patients with UGTB. Treatment regimens of 6 months are effective in most patients. ${ }^{36}$ Patients with HIV and tuberculosis being treated with HAART should be carefully observed with respect to sequencing of treatment, the value of directly observed therapy, and the possibility of pharmacokinetic drug interactions that could result in toxicities, particularly hepatotoxicity and neuropathy.

Despite effective drug therapy, surgery in the form of ablation (e.g. nephrectomy) or reconstruction (e.g. augmentation enterocystoplasty) might be unavoidable. Both radical and reconstructive surgery should be carried out after at least 2 months of intensive anti-TB drug therapy. $\underline{33}$

\section{PROSTATITIS AND PROSTATIC ABSCESS}

The estimated incidence of acute bacterial prostatitis increases from $1 \%$ to $2 \%$ in the general population to $3 \%$ in asymptomatic HIV-positive patients and $14 \%$ in patients with AIDS. $\frac{39}{9}$ The incidence of prostatic abscesses in patients with AIDS, however, has substantially decreased with the advent of HAART; abscesses usually only occur in patients with very low $\mathrm{CD} 4^{+}$counts. $\underline{14}$

Urine culture is usually negative in men with prostatitis and AIDS, but cultures from the prostate can show unusual organisms such as $S$. aureus, Enterococcus spp., M. tuberculosis, $M$. avium, Cryptococcus spp., H. capsulatum, C. albicans, or cytomegalovirus. $\underline{40,41,42}$

$\mathrm{CT}$ and transrectal ultrasound of the prostate are both accurate methods of diagnosing prostatic disorders in patients with HIV; transrectal ultrasound is perhaps the more useful modality if aspiration or biopsy is required. $\underline{20}$ A prostatic abscess can be managed with aspiration, drainage through the perineal route, or transurethral unroofing. Antibiotic therapy should initially include parenteral bactericidal agents such as broad-spectrum penicillin derivatives, third-generation cephalosporins with or without aminoglycosides, or fluoroquinolones. $\frac{14,20}{2}$ Long-term antibiotic therapy is essential to avoid recurrent infection. ${ }^{43}$ 


\section{EPIDIDYMO-ORCHITIS AND FOURNIER GANGRENE}

In sub-Saharan Africa, tuberculous epididymitis is often reported in patients with AIDS. Fungal infection with $\mathrm{H}$. capsulatum, as well as cytomegalovirus, can involve the testis and epididymis (or both testes and epididymes) in HIV-positive men. $\underline{44}$

Fournier gangrene (necrotizing fasciitis of the external genitalia) can be the first clinical presentation in patients with HIV infection. $\frac{6,45,46}{} \mathrm{Immediate}$ diagnosis with wide surgical debridement of necrotic and nonviable tissue is necessary. .77 Broad-spectrum antibiotic therapy for aerobic Gram-positive and Gram-negative bacteria, as well as for anaerobic microorganisms, is necessary while awaiting the

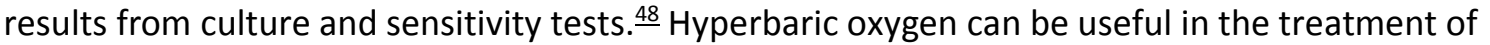
Fournier gangrene. $\frac{49}{}$

\section{PARASITIC INFESTATIONS}

Regions with a high prevalence of helminthic parasite infestations also have a high prevalence of HIV and AIDS. .50 Interaction of the pathogen with host CD4 ${ }^{+} T$ cells is a characteristic of HIV infection as well as parasitic infestations, and parasitic infection can alter the disease course of tropical diseases such as schistosomiasis and malaria. On the other hand, tropical infections can ease transmission of HIV and accelerate progression from asymptomatic HIV infection to AIDS. $\underline{51}$

In rural Africa, women with genital schistosomiasis have a three-fold higher risk of having HIV than women who do not have schistosomiasis. $\underline{52}$ In addition, HIV-positive women are more likely to have malaria or lymphatic filariasis than are HIV-negative women. Mother to child transmission of HIV is substantially more likely in women coinfected with one or more helminthic parasite than in those with no helminthic infection; transmission possibly takes place via a mechanism in which parasite antigens activate lymphocytes in utero. $\underline{\underline{53}}$

HIV infection can hinder the diagnosis of parasitic infestations, or reduce the efficacy of antiparasitic

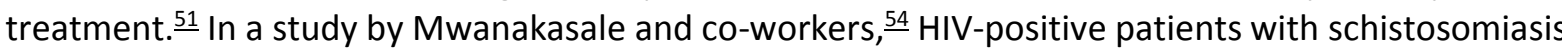
excreted fewer parasite eggs and had fewer symptoms of hematuria than HIV-negative patients; the sensitivity and positive predictive value of hematuria as an indication of substantial infection was lower in the group of patients coinfected with HIV.

\section{MALIGNANCIES ASSOCIATED WITH HIV AND AIDS}

AIDS-associated malignancies (AAMs) include Kaposi sarcoma, non-Hodgkin lymphoma and invasive cervical cancer. In the past decade there has been a significant reduction in the incidence of Kaposi sarcoma and non-Hodgkin lymphoma in patients with AIDS, probably as a result of HAART; the incidence of cervical carcinoma, however, has not decreased. $.55,56,57$ On the other hand, HIV-positive patients still have a higher risk of developing Kaposi sarcoma and non-Hodgkin lymphoma than the general population. $\frac{58}{\text { From }} 1992$ to 2002, the most common malignancies in the HIV-positive population were Kaposi sarcoma, lymphoma (Hodgkin and non-Hodgkin), cervical cancer, liver cancer, testicular cancer, and melanoma. $\underline{59}$

In patients with HIV on HAART there has been an increase in the incidence of non-AAMs, including anal cancer, lung cancer, hepatocarcinoma, vaginal cancer, leukemia, oropharyngeal cancer, colorectal cancer, penile cancer, and renal cancer. $\frac{55,56,57,59,60}{5}$

Non-AAMs - such as lung, skin, penile, laryngeal, tongue and colorectal cancer-are likely to occur at a younger age in HIV-positive patients than in HIV-negative individuals (47.6 years vs 60.3 years); HIVpositive patients also seem to have a lower clinical stage of disease with these cancer types. Patients with HIV and a non-AAM are usually quite young at diagnosis; this fact might be partly associated with early detection and pre-existing immunosuppression. $\underline{.61}$ 
Possible explanations for the high prevalence of non-AAMs might include the following factors: longer survival of patients on HAART, with only partial immune recovery achieved in most patients; high incidence of human papillomavirus (HPV), Epstein-Barr virus, and hepatitis C virus coinfection in patients with HIV infection; and potential oncogenicity of long-term HIV infection or long-term HAART. $\underline{62}$ Other proposed mechanisms of carcinogenesis include decreased immune surveillance, a direct effect of viral proteins, cytokine dysregulation, or other immunologic or viral cofactors. $\underline{63}$

The outcome for HIV-infected patients with cancer has substantially improved in the HAART era, probably due to the fact that the treatment considerably improves the immune status and bone marrow function. Current studies suggest that patients with AAMs can be treated with conventional modalities such as chemotherapy and radiotherapy and with appropriate use of supportive measures..$\underline{64}$

\section{KAPOSI SARCOMA}

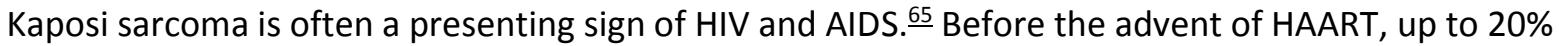
of patients infected with HIV were affected by Kaposi sarcoma. This percentage has decreased by approximately $90 \%$ since the introduction of HAART. $\underline{66}$ The cause of this rare cancer is human herpes virus type $8 . \frac{66}{}$ Kaposi sarcoma is more common in men and usually comprises a systemic disease that affects internal organs, including the kidneys and testes. .77 About $20 \%$ of HIV-positive men with Kaposi sarcoma have genital involvement, which can lead to complications such as lymphatic or urethral obstruction or (rarely) penile necrosis and gangrene as a result of vasculitis or vascular obstruction (Figure 2).$\underline{68}$

The first step in treatment for Kaposi sarcoma in patients with HIV is to initiate HAART or to optimize the HAART regimen, which generally results in remission of Kaposi sarcoma. ${ }^{69}$ Local therapy for cosmetically disturbing or painful lesions can include the following treatment options: laser therapy; cryotherapy; surgical excision; application of topical retinoids (e.g. 9-cis-retinoic acid and alitretinoin); use of intralesional bleomycin, interferons or vinca alkaloids; $\mathrm{X}$-ray radiation; electron beam therapy; or cobalt radiation. .6 Disseminated or visceral Kaposi sarcoma is treated with combination chemotherapy. The gold standard combination therapy of adriamycin, bleomycin and vincristine has been replaced in recent years with liposomal anthracyclines, such as daunorubicin and doxorubicin. $\underline{69,70}$ Paclitaxel is also effective in treating advanced Kaposi sarcoma. $\underline{71}$ Suprapubic cystostomy might be necessary until definitive treatment takes place. $\stackrel{72}{ }$ Despite widespread availability of HAART and chemotherapy, Kaposi sarcoma continues to be a substantial clinical problem in patients with HIV, with only $50 \%$ of individuals achieving complete resolution of disease. $\underline{\underline{73}}$

\section{TESTICULAR TUMORS}

Early studies have suggested that the incidence of testicular tumors in immunocompromised patients is between 20 times and 57 times that of the general population, and that germ cell testicular tumors are the third most common AIDS-associated malignancy. $\underline{74}$ Despite the high prevalence of HIV infection in sub-Saharan Africa, there have been no reports of a significant increase in germ cell testicular tumors in this region. A more recent study indicated that the relative risk for testicular seminoma in HIV-positive patients compared with HIV-negative individuals is around 2. $\frac{75}{}$ NonHodgkin lymphoma of the testes can present bilaterally and is usually disseminated at the time of presentation. $\underline{76}$ Once considered to be poor candidates for radiation and chemotherapy, HIV-positive patients with non-Hodgkin lymphoma of the testes are currently thought to have equal morbidity and response to patients who do not have HIV. .77 Complete remission is reported in $50-75 \%$ of patients with systemic treatment; $\underline{78}$ however, the incidence of relapse and rapid progression might be higher in immunocompromised men than in the general population. $\underline{14,15}$ 


\section{PENILE CANCER}

Individuals infected with specific HPV subtypes are at risk of developing squamous cell carcinomas after a long period of latency (Figure 3 ).$\stackrel{79}{ }$ About $40-45 \%$ of patients with penile carcinoma have evidence of HPV DNA; $\underline{\underline{80}}$ however, factors other than HPV can also play a part in the pathogenesis of penile cancer. $\underline{.1}$

Certain types of HPV are associated with squamous cell carcinoma (igure 3 ). In a study of HIVinfected men, a high prevalence of high-risk HPV types (16 and 18) was found in the anus, penis and mouth (78\%, 36\% and $30 \%$, respectively), without evidence of pathology in these areas. $\frac{82}{\text { The }}$ relative risk of penile cancer in HIV-positive patients is four times higher than that in HIV-negative men. $\underline{75}$

HIV-infected homosexual men have a substantially increased risk of HPV-induced anal cancer and anal intraepithelial neoplasia, and a moderately increased risk of penile cancer. $\underline{83}$ In a study by Kreuter and colleagues ${ }^{84}$ of HIV-positive men, penile intraepithelial neoplasia was detected in $4.2 \%$ and anal intraepithelial neoplasia was found in $59 \%$ of these patients. Urethral and bladder involvement with condylomata acuminata caused by HPV is usually associated with immunosuppression. $\frac{85}{5}$

Squamous cell carcinoma of the penis is usually more aggressive in HIV-positive patients than in individuals without HIV and should be excised and staged. Regional lymphadenectomy, radiation, or systemic chemotherapy should be used, in a similar approach to treatment for individuals not infected with HIV. $\underline{86}$

\section{PROSTATE CANCER}

It is not clear whether there is a decreased incidence of prostate and breast cancer in HIV-positive

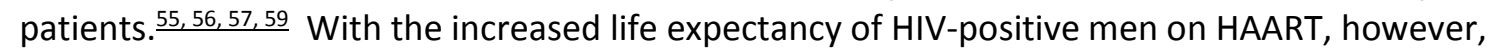
prostate cancer in this population is expected to become an increasingly more important health problem.

Despite a case report suggesting that prostate cancer in HIV-positive men might be unusually aggressive, ${ }^{87}$ prostate cancer has a similar disease course in men with HIV as that in HIV-negative men. With improved therapies for HIV and increasing survival, the importance of screening for and treating prostate cancer is increasing. $\underline{88}$

It has been recommended that the standard PSA assessment should be done in HIV-positive patients, without the need for adjustments. $\frac{89}{}$ Some clinicians advocate PSA screening of HIV-positive patients in their early forties because of the potential for prostate cancer to present in a disseminated manner with nonspecific features. $.87,90$

HIV-positive patients who have asymptomatic prostate cancer should be offered all possible treatment options, including surgery, radiation, androgen deprivation, and observation. Some clinicians believe that laparoscopic or robot-assisted surgery should be performed when possible to minimize the risk of postsurgery complications. ${ }^{91}$ In a meta-analysis of 12 publications providing detailed information on 60 patients with HIV and prostate cancer, early outcomes of treatment did not demonstrate increased acute morbidity; however, long-term outcomes have not been reported. $\underline{88}$ 


\section{SEXUAL DYSFUNCTION AND INFERTILITY IN PATIENTS WITH HIV AND AIDS}

\section{ERECTILE DYSFUNCTION}

Testicular atrophy is common in men with AIDS and can predispose patients to infertility, erectile dysfunction (ED) and reduced libido. Studies both support and oppose the occurrence of sexual dysfunction in HIV-positive men taking HAART. $\underline{.92,93,94,95}$ Men who are HIV positive are more likely to have symptoms of depression than are men without HIV. $\underline{.96,97}$ This correlation might be associated with low libido and ED; however, common antidepressant medications such as selective serotonin reuptake inhibitors can also decrease libido and sexual performance..$\underline{98}$ Phosphodiesterase- 5 inhibitors might allow patients to recommence sexual activity and regain confidence, which can improve depressive symptoms. .99 The use of testosterone in muscle-wasting disorders such as HIV has also been suggested as a treatment option. $\underline{.00}$

Effective treatment of ED can increase the risk of spreading HIV. .01 Benotschet al. $\frac{102}{}$ have shown that men who took phosphodiesterase- 5 inhibitors had higher rates of sexually risky behavior. This observation means that there might be an ethical dilemma in treating ED in HIV-positive patients. .03 It is important to improve patients' quality of life, but equally important to help stop the spread of the virus; therefore, detailed counseling of HIV-positive men with ED is essential. .04

\section{INFERTILITY}

Abnormal semen parameters can be associated with atrophy of the testes. Atrophy might be the result of hypothalamopituitary axis dysfunction, inflammation, infection, chronicity of disease, malnutrition, or a direct cytotoxic effect of HIV on germinal tissue. $\underline{77}$

If an infertile couple with one HIV-positive partner wants to have a child, the risk of HIV transmission has to be considered. HIV transmission rates for unprotected heterosexual intercourse are 1 case per 1,000 contacts (male to female transmission) to less than 1 case per 1,000 contacts (female to male transmission). .05 Sperm washing for couples where the man is infected with HIV, followed by assisted reproduction techniques, has proved to be the safest method for infertility treatment in HIV-positive couples. $\stackrel{106,107}{10}$ Tested sperm carry a $10 \%$ risk of harboring the virus, so patients and offspring are still at risk; however, more than 500 children have been born after sperm washing, with no instances of seroconversion. $\underline{\underline{105}}$

\section{UROLOGIC COMPLICATIONS AFTER ANTIRETROVIRAL TREATMENT}

\section{UROLITHIASIS}

Indinavir is an antiretroviral drug that works as a protease inhibitor and prevents the formation of new viral particles. About $20 \%$ of indinavir is not metabolized and is excreted in the urine. $.108,109,110,111$ The drug can cause intrarenal crystal deposition, which can lead to acute renal failure. $\frac{112}{\mathrm{~A}}$ total of $80 \%$ of patients with urologic complications have raised indinavir plasma concentrations, indicating that plasma levels should be carefully monitored and the indinavir dosage reduced if necessary. $\underline{113,114}$

Indinavir causes urolithiasis in 5-25\% of HIV-positive patients treated with the drug. $.115,116$ Contributing causes of urolithiasis include diarrhea leading to dehydration, increased urinary concentration, acidification, and hypocitraturia. $\frac{115,117}{1 n d i n a v i r}$ is reported as a stone component in only $29 \%$ of calculi. The remaining stone components are calcium oxalate, ammonium acid urate, and uric acid. $\underline{115,117}$

Urolithiasis can in turn cause acute renal colic or severe azotemia. Pure indinavir stones are radiolucent and might escape detection by plain X-ray and CT (Figure 4). $.112,115,118,119,120$ Treatment 
consists of interrupting indinavir administration temporarily, giving narcotic analgesics, increasing oral fluid intake (until urine production reaches $2 \mathrm{l} /$ day or more) and acidifying the urine by oral administration of the amino acid L-methionine. $\frac{111,118,119}{10}$ Double-J ureteral stents can be inserted if

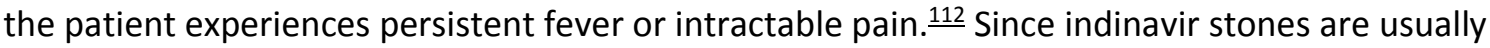
gelatinous in consistency, extracorporeal shock wave lithotripsy will not be effective. $\underline{112,120}$

\section{RENAL DYSFUNCTION}

HAART regimens have a relatively low but clinically significant nephrotoxic potential. ${ }^{121}$ Acute tubular toxicity, crystal nephropathy, and acute interstitial nephritis are among the common renal manifestations of HAART nephrotoxicity. Adefovir and tenofovir are associated with tubular toxicity. Indinavir is associated with crystalluria, crystal nephropathy and nephrolithiasis. Acute interstitial nephritis has been reported in patients taking indinavir and atazanavir. Rarely, enfuvirtide can promote glomerulopathy. Frequent exposure to other nephrotoxic non-antiretroviral drugs (e.g. antibiotics, antifungals) also contributes to kidney disease. $\underline{122}^{122}$

\section{HIV PREVENTION AND MALE CIRCUMCISION}

The mainstay of HIV prevention is the so-called ABC approach (abstinence, 'be faithful', condom use). Mother to child transmission can be minimized if cesarean section is performed along with intrapartum infusion of antiviral medications. $\underline{15}$

The hypothesis that uncircumcised men are at greater risk of acquiring HIV or other sexually transmitted infections than men who have been circumcised is based on several plausible biological mechanisms. These mechanisms include susceptibility of the mucosal surface of the prepuce to trauma, longer survival of pathogens in warm and moist subpreputial spaces, and lack of keratinization and high density of HIV target cells in the inner foreskin compared with the keratinized surface of the outer foreskin and glans. $\frac{123,124,125,126,127}{}$

Epidemiological studies in areas with a low prevalence of male circumcision and a high prevalence of HIV support this hypothesis. $\frac{128,129}{1}$ A meta-analysis of studies that adjusted for potential confounders reported a large and highly significant reduced risk of HIV infection in circumcised men (adjusted risk ratio 0.42$) \cdot \underline{.123,130}$

Three prospective, randomized clinical trials of adult male circumcision in South Africa, Kenya, and Uganda have reported highly significant reductions in risk of HIV infection among participants randomly assigned to circumcision. $\frac{131,132,133}{}$ The overall risk ratio compared with no circumcision was $0.42(95 \% \mathrm{Cl} 0.31-0.57)$, which corresponds with a $58 \%$ increase in protection $(95 \% \mathrm{Cl} 43-$ $69 \%) .{ }^{134}$ Apart from absolute sexual abstinence and rigorous condom use, there is currently no preventive measure that has been shown to be more effective than adult male circumcision.

\section{CONCLUSIONS}

Since the advent of HAART, the prognosis of HIV-infected patients has improved dramatically and the life expectancy for patients with access to HAART currently seems to be similar to that of HIVnegative individuals. Urologic complications in HIV-infected patients who receive HAART are mostly resultant adverse effects of treatment, in particular renal dysfunction, which is in many cases due to antiviral, antibacterial or antifungal medication, and urolithiasis, caused by the antiretroviral drug indinavir. In patients who do not have access to HAART the prognosis of HIV remains dismal, with eventual progression to AIDS and death being virtually inevitable. Urologic complications in patients with HIV are often the result of opportunistic infections by mycobacteria, parasites, fungi and viruses, or comprise unusual malignancies such as Kaposi sarcoma and non-Hodgkin lymphoma. Prospective clinical trials have conclusively shown that adult male circumcision reduces the risk of female to male 
HIV transmission by more than $50 \%$, which is a higher success rate than any other preventive measure except complete sexual abstinence, absolute monogamy or rigorous condom use. Further research is needed to develop preventive or curative modalities with significantly greater efficacy and fewer adverse effects than the currently available options.

\section{KEY POINTS}

- Several regions worldwide still do not have access to highly active antiretroviral therapy (HAART); patients with HIV who do not receive HAART are at a high risk of developing opportunistic infections, which usually originate in urologic organs

- Urologic complications are often the first clinical signs of HIV and AIDS

- In patients with HIV and AIDS, urologic complications are typically the result of infection by mycobacteria, parasites, fungi and viruses

- Urologic complications of HIV and AIDS include renal dysfunction, urinary tract infection, bladder dysfunction, urogenital tuberculosis, prostatitis, prostatic abscess, epididymo-orchitis, Fournier gangrene, urologic malignancies, sexual dysfunction and infertility

- There is some evidence that adverse effects of HAART cause urologic complications such as urolithiasis and renal dysfunction

- Prospective clinical trials have shown that adult male circumcision reduces the risk of female to male HIV transmission by more than $50 \%$; however, further research is still needed 


\section{BOX 1 UROLOGIC COMPLICATIONS OF HIV AND}

\section{AIDS.}

Kidneys

- Renal dysfunction and/or renal failure

- HIV-associated nephropathy

- Nephrotoxicity from medication (e.g. from HAART)

- Renal abscess

- Renal tuberculosis

- Urolithiasis (especially indinavir stones)

Ureters

- Obstruction by tuberculosis or malignancy (e.g. lymphoma)

Bladder

- Urinary tract infection by Gram-negative or Grampositive bacteria, or by atypical pathogens (e.g. mycobacteria, fungi, parasites and viruses)

- Voiding dysfunction (caused by neurological disorders or bladder outlet obstruction)

Prostate

- Prostatitis and prostate abscess

- Prostate cancer

Scrotum and testes

- Epididymo-orchitis

- Fournier gangrene

- Kaposi sarcoma

- Germ cell testis tumor

- Non-Hodgkin lymphoma

- Hypogonadism

- Erectile dysfunction

- Infertility

Penis

- Condylomata acuminata (caused by human papillomavirus infection)

- Squamous cell carcinoma

Abbreviation: HAART, highly active antiretroviral therapy. 


\section{Figures}

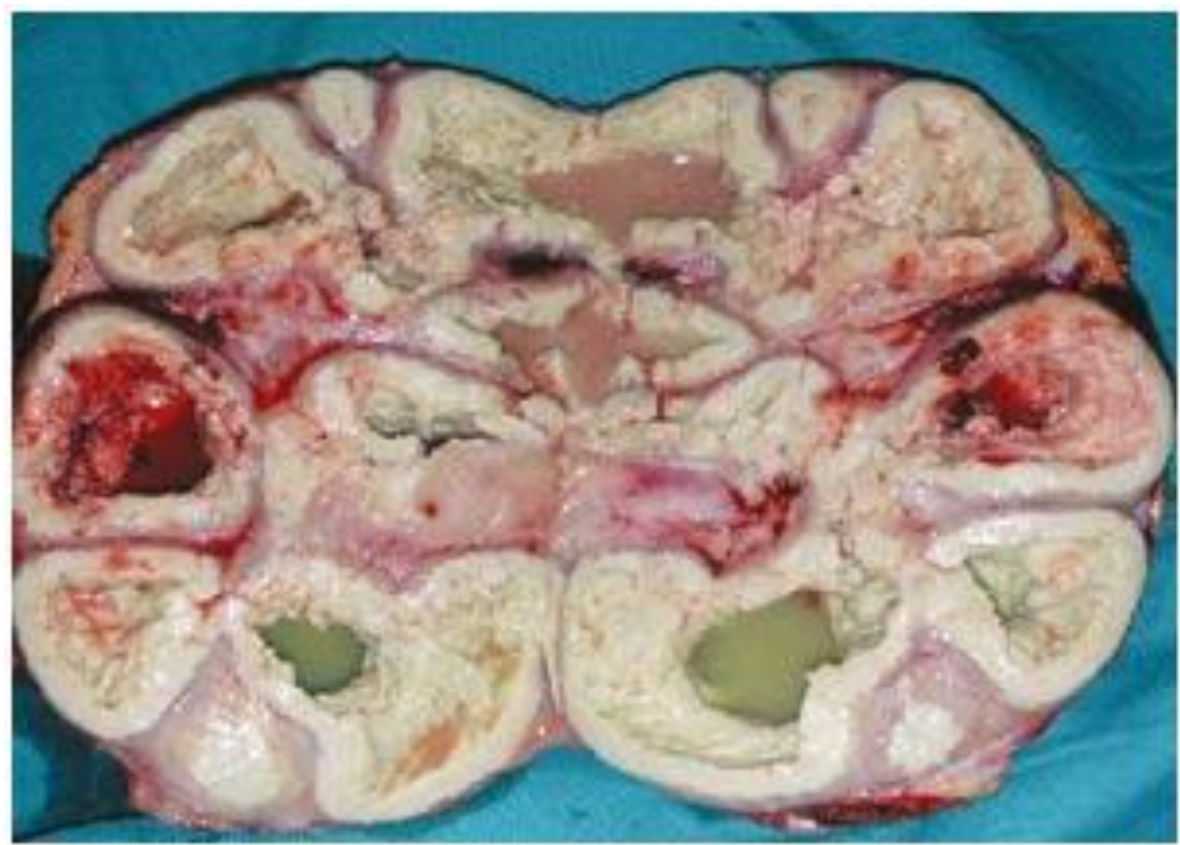

Figure 1 Tuberculous pyonephrosis with widespread caseous necrosis of the renal parenchyma in an HIV-positive patient with a low $\mathrm{CD}^{+}$cell count

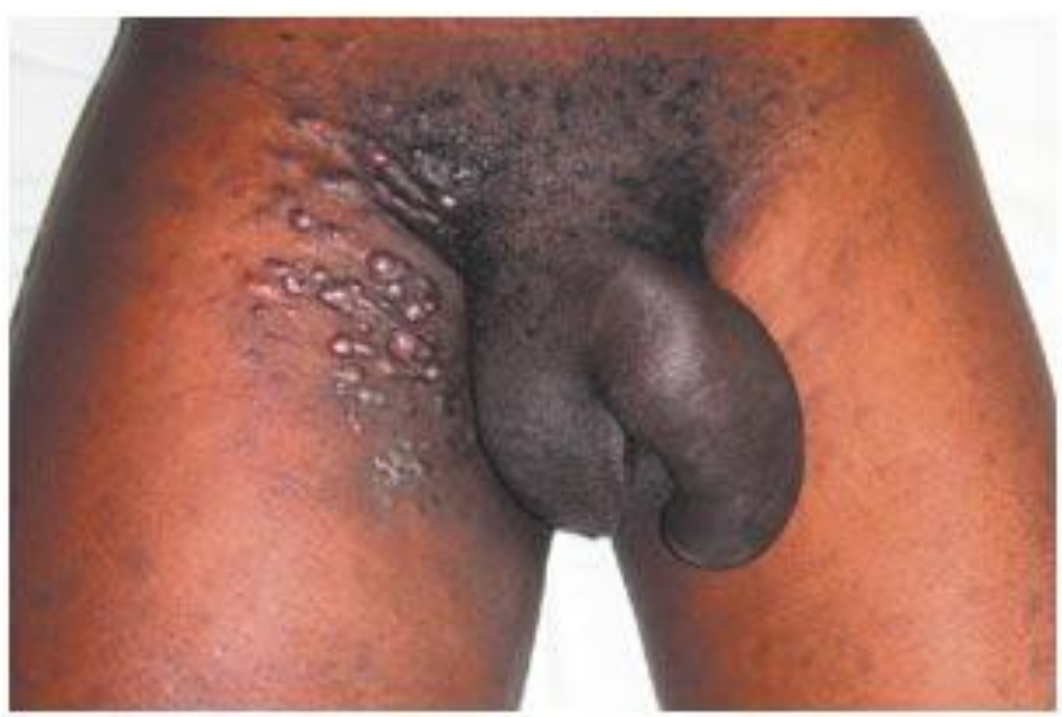

Figure 2 Kaposi sarcoma causing lymphedema of the penis, scrotum and right leg due to inguinopelvic lymph-node metastases in an HIV-positive man 


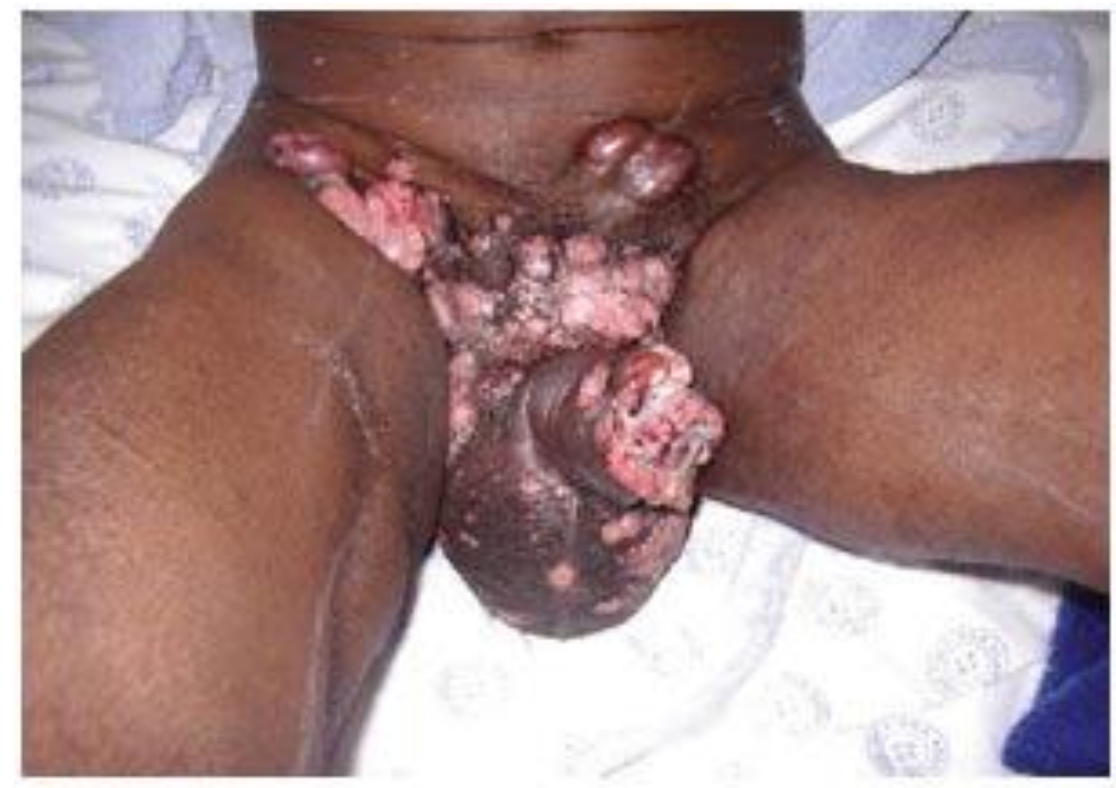

Figure 3 Extensive squamous cell carcinoma of the penis involving the scrotum and inguinal lymph nodes in an HIV-positive patient with a low $\mathrm{CD}^{+}$cell count

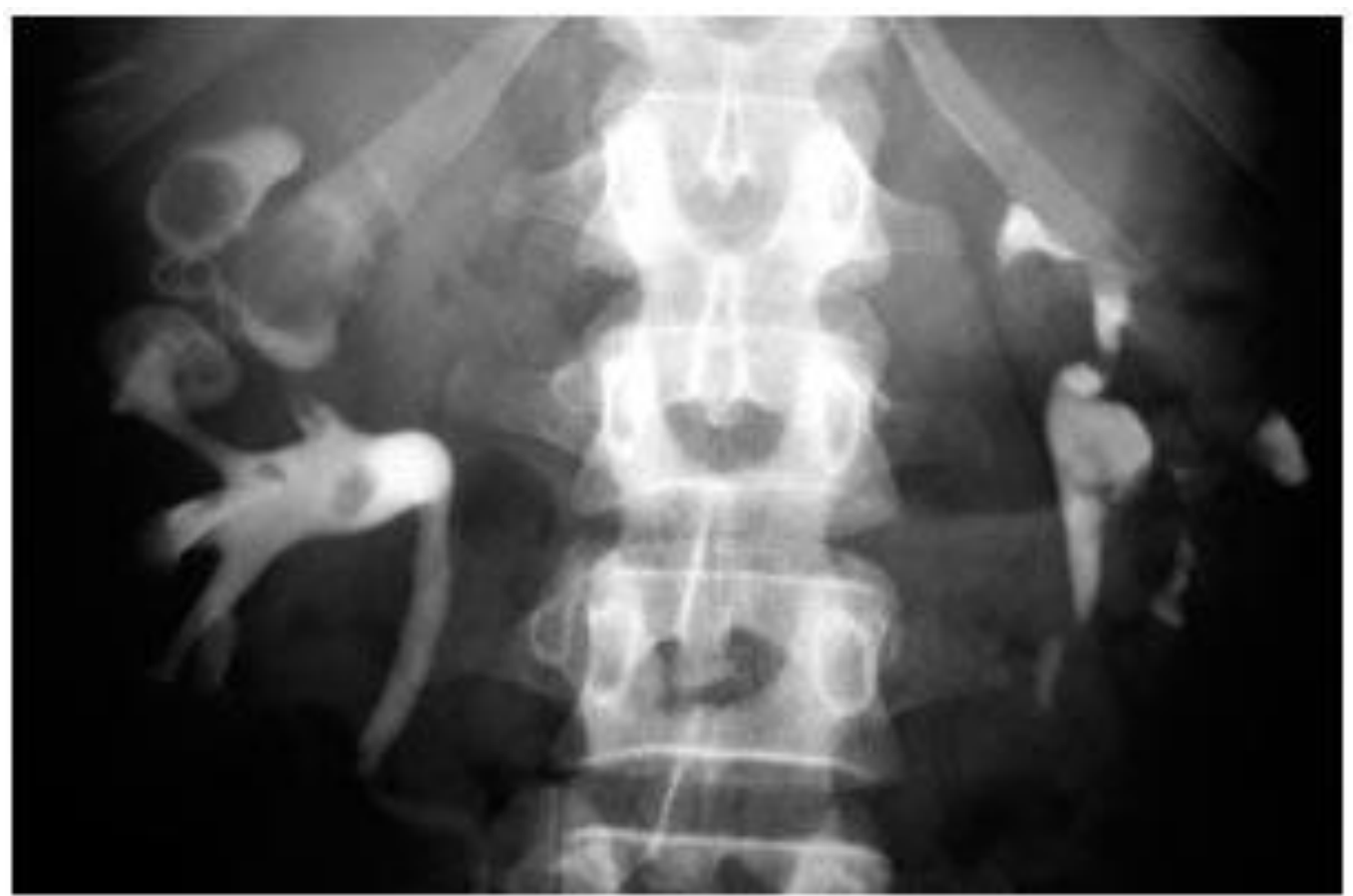

Figure 4 Excretory urogram (intravenous pyelogram) shows filling defects in the renal collecting system due to urolithiasis in a patient with AIDS receiving treatment with indinavir 


\section{REFERENCES}

1. WHO (online 20 November 2007) Global HIV prevalence has levelled off. [http://www.who.int/mediacentre/news/releases/2007/pr61/en/]

2. Buvé A et al. (2002) The spread and effect of HIV-1 infection in sub-Saharan Africa. Lancet 359: 2011-2017

3. HIV and AIDS in Africa [http://www.avert.org/aafrica.htm]

4. UNAIDS (online 20 November 2007) 2007 AIDS epidemic update. [http://www.unaids.org/en/KnowledgeCentre/HIVData/EpiUpdate/EpiUpdArchive/2007/]

5. UNAIDS/WHO (2006) AIDS epidemic update: December 2006. [http://data.unaids.org/pub/EpiReport/2006/]

6. Lebovitch S and Mydlo JH (2008) HIV-AIDS-urologic considerations. Urol Clin N Am 35: 5968

7. Roe J et al. (2008) HIV care and the incidence of acute renal failure. Clin Infect Dis 47: 242249

8. Rieke A (2007) HIV and renal function. In HIV Medicine 2007, 567-580 (Eds Hoffmann C. et al.) [http://www.hivmedicine.com/hivmedicine2007.pdf] (accessed 1 December 2008)

9. Shah SN et al. (2006) Update on HIV-associated nephropathy. Curr Opin Nephrol. Hypertens 15: 450-455

10. Gerntholtz TE et al. (2006) HIV-related nephropathy: a South African perspective. Kidney Int 69: 1885-1891

11. Atta MG et al. (2008) HIV-associated nephropathy: epidemiology, pathogenesis, diagnosis and management. Expert Rev Anti Infect Ther 6: 365-371

12. Janakiraman $\mathrm{H}$ et al. (2008) Correlation of CD4 counts with renal disease in HIV positive patients. Saudi J Kidney Dis Transp/ 19: 603-607

13. Comiter S et al. (1992) Ureteral obstruction in a patient with Burkitt's lymphoma and AIDS. Urology 39: 277-280

14. Hyun $G$ and Lowe CF (2003) AIDS and the urologist. Urol Clin N Am 30: 101-109

15. Heyns CF and Fisher M (2005) The urological management of the patient with acquired immunodeficiency syndrome. BJU Int 95: 709-716

16. Gruber SA et al. (2008) Preliminary experience with renal transplantation in HIV+ recipients: low acute rejection and infection rates. Transplantation 86: 269-274

17. Miles BJ et al. (1989) The urological manifestations of the acquired immunodeficiency syndrome. J Urol 142: 771-773

18. Zouiten F et al. (2003) Bacterial infections in AIDS (mycobacterial infections excluded): study of 100 cases [French]. Tunis Med 81: 113-120

19. Hoepelman Al et al. (1992) Bacteriuria in men infected with HIV-1 is related to their immune status (CD4+ cell count). AIDS 6: 179-184

20. Lee LK et al. (2001) The urologist and the patient infected with human immunodeficiency virus or with acquired immunodeficiency syndrome. BJU Int88: 500-510

21. Schönwald S et al. (1999) Urinary tract infections in HIV disease. Int J Antimicrob Agents 11: 309-311

22. Kwan DJ and Lowe FC (1995) Genitourinary manifestations of the acquired immunodeficiency syndrome. Urology 45: 13-27

23. Vignesh R et al. (2008) Urinary infections due to multi-drug-resistantEscherichia coli among persons with HIV disease at a tertiary AIDS care centre in South India. Nephron Clin Pract 110: c55-c57

24. Steele BW and Carson CC (1997) Recognizing the urologic manifestations of HIV and AIDS. Contemp Urol 9: 39-53

25. Kaplan MS et al. (1987) Urologic manifestations of AIDS. Urology 30: 441-443

26. O'Regan S et al. (1990) AIDS and the urinary tract. J Acquir Immune Defic Syndr 3: 244-251

27. Rey D et al. (1999) Isolated renal Aspergillus abscess in an AIDS patient with a normal CD4+ cell count on highly active antiretroviral therapy. Eur J Clin Microbiol Infect Dis 18: 137-141 
28. Padoveze MC et al. (2002) Nosocomial infections among HIV-positive and HIV-negative patients in a Brazilian infectious diseases unit. Am J Infect Control30: 346-350

29. Menéndez V et al. (1995) Neurogenic bladder in patients with acquired immunodeficiency syndrome. Neurourol Urodyn 14: 253-257

30. Hermieu JF et al. (1996) Micturition disturbances and human immunodeficiency virus infection. J Urol 156: 157-159

31. Gyrtrup HJ et al. (1995) Voiding problems in patients with HIV infection and AIDS. Scand J Urol Nephrol 29: 295-298

32. Gluckman GR and Werboff LH (1994) Toxoplasmosis of the bladder: case report and review of the literature. J Urol 151: 1629-1630

33. Figueiredo AA et al. (2008) Urogenital tuberculosis in immunocompromised patients. Int Urol Nephrol [doi:doi:10.1007/s11255-008-9436-6]

34. Centers for Disease Control and Prevention (online 28 January 2008) TB and HIV/AIDS. [http://www.cdc.gov/hiv/resources/factsheets/hivtb.htm]

35. Dean GL et al. (2002) Treatment of tuberculosis in HIV-infected persons in the era of highly active antiretroviral therapy. AIDS 16: 75-83

36. Cek $\mathrm{M}$ et al. for the Members of the Urinary Tract Infection (UTI) Working Group of the European Association of Urology (EAU) Guidelines Office (2005)EAU guidelines for the management of genitourinary tuberculosis. Eur Uro/48: 353-362

37. Manosuthi W et al. (2006) Immune reconstitution inflammatory syndrome of tuberculosis among HIV-infected patients receiving antituberculous and antiretroviral therapy. J Infect Dis 53: $357-363$

38. Colebunders R et al. (2006) Tuberculosis immune reconstitution inflammatory syndrome in countries with limited resources. Int J Tuberc Lung Dis 10: 946-953

39. Leport C et al. (1989) Bacterial prostatitis in patients infected with the human immunodeficiency virus. J Urol 141: 334-336

40. Trauzzi SJ et al. (1994) Management of prostatic abscess in patients with human immunodeficiency syndrome. Urology 43: 629-633

41. Gebo KA (2002) Prostatic tuberculosis in an HIV infected male. Sex Transm Infect 78: 147148

42. Hedayati T and Kwon DS (online 5 November 2007) Prostatitis. [http://www.emedicine.com/emerg/topic488.htm]

43. Wise GJ and Shteynshlyuger A (2006) How to diagnose and treat fungal infections in chronic prostatitis. Curr Urol Rep 7: 320-328

44. Kahn DG and Thommes J (1992) Granulomatous orchitis and epididymitis secondary to Histoplasma capsulatum and CMV in AIDS [abstract \#PuB 7267]. In Proceedings of the International Conference on AIDS: 1992 July 19-24; Amsterdam, The Netherlands

45. Ayan F et al. (2005) Fournier's gangrene: a retrospective clinical study on forty-one patients. ANZ J Surg 75: 1055-1058

46. Corman JM et al. (1999) Fournier's gangrene in a modern surgical setting: improved survival with aggressive management. BJU Int 84: 85-88

47. Dahm P et al. (2000) Outcome analysis in patients with primary necrotizing fasciitis of the male genitalia. Urology 56: 31-35

48. Jeong HJ et al. (2005) Prognostic factors in Fournier gangrene. Int J Urol 12: 1041-1044

49. Mindrup SR et al. (2005) Hyperbaric oxygen for the treatment of Fournier's gangrene. J Urol 173: 1975-1977

50. Secor WE and Sundstrom JB (2007) Below the belt: new insights into potential complications of HIV-1/schistosome coinfections. Curr Opin Infect Dis20: 519-523

51. Harms $G$ and Feldmeier H (2005) The impact of HIV infection on tropical diseases. Infect Dis Clin North Am 19: 121-135

52. Kjetland EF et al. (2006) Association between genital schistosomiasis and HIV in rural Zimbabwean women. AIDS 20: 593-600

53. Gallagher $M$ et al. (2005) The effects of maternal helminth and malaria infections on motherto-child HIV transmission. AIDS 19: 1849-1855 
54. Mwanakasale V et al. (2003) Interactions between Schistosoma haematobiumand human immunodeficiency virus type 1: the effects of coinfection on treatment outcomes in rural Zambia. Am J Trop Med Hyg 69: 420-428

55. Nutankalva L et al. (2008) Malignancies in HIV: pre- and post-highly active antiretroviral therapy. J Natl Med Assoc 100: 817-820

56. Mayor AM et al. (2008) AIDS-defining neoplasm prevalence in a cohort of HIV-infected patients, before and after highly active antiretroviral therapy. Ethn Dis 18 (Suppl 2): S189S194

57. Lewden C et al. for the ANRS EN19 Mortalité Study Group and Mortavic1 (2008) Changes in causes of death among adults infected by HIV between 2000 and 2005: the "Mortalité 2000 and 2005" surveys (ANRS EN19 and Mortavic). J Acquir Immune Defic Syndr 48: 590-598

58. Engels EA et al. for the HIV/AIDS Cancer Match Study (2006) Trends in cancer risk among people with AIDS in the United States: 1980-2002. AIDS 20: 1645-1654

59. Patel P et al. for the Adult and Adolescent Spectrum of Disease Project and HIV Outpatient Study Investigators (2008) Incidence of types of cancer among HIV-infected persons compared with the general population in the United States, 1992-2003. Ann Intern Med 148: 728-736

60. Spano JP et al. (2008) AIDS-related malignancies: state of the art and therapeutic challenges. J Clin Oncol[doi:doi:10.1200/JCO.2008.16.8252]

61. Demopoulos BP et al. (2003) Non-acquired immunodeficiency syndrome-defining malignancies in patients infected with human immunodeficiency virus.Arch Pathol Lab Med 127: 589-592

62. Bedimo R (2008) Non-AIDS-defining malignancies among HIV-infected patients in the highly active antiretroviral therapy era. Curr HIV/AIDS Rep 5: 140-149

63. Bellan C et al. (2003) Pathologic aspects of AIDS malignancies. Oncogene 22: 6639-6645

64. Rosso R et al. (2008) Infectious complications of cancer chemotherapy in HIV patients. Curr Infect Dis Rep 10: 149-156

65. Lowe FC et al. (1989) Kaposi's sarcoma of the penis in patients with acquired immunodeficiency syndrome. J Urol 142: 1475-1477

66. Schöfer H and Sachs DL (2007) Kaposi's sarcoma. In HIV Medicine 2007, 477-488 (Eds Hoffmann C. et al.) [http://www.hivmedicine.com/hivmedicine2007.pdf] (accessed 1 December 2008)

67. Tappero JW et al. (1993) Kaposi's sarcoma: epidemiology, pathogenesis, histology, clinical spectrum, staging criteria and therapy. J Am Acad Dermato/28: 371-395

68. Klein LT and Lowe FC (1995) Penile gangrene associated with extensive Kaposi's sarcoma in patients with the acquired immunodeficiency syndrome.Urology 46: 425-428

69. Lichterfeld M et al. (2005) Treatment of HIV-1-associated Kaposi's sarcoma with pegylated liposomal doxorubicin and HAART simultaneously induces effective tumor remission and CD4+ T cell recovery. Infection 33: 140-147

70. Martin-Carbonero L et al. (2004) Pegylated liposomal doxorubicin plus highly active antiretroviral therapy versus highly active antiretroviral therapy alone in HIV patients with Kaposi's sarcoma. AIDS 18: 1737-1740

71. Tulpule A et al. (2002) Multicenter trial of low-dose paclitaxel in patients with advanced AIDS-related Kaposi sarcoma. Cancer 95: 147-154

72. Swierzewski SJ III et al. (1993) The management of meatal obstruction due to Kaposi's sarcoma of the glans penis. J Urol 150: 193-195

73. Nguyen HQ et al. (2008) Persistent Kaposi sarcoma in the era of highly active antiretroviral therapy: characterizing the predictors of clinical response. AIDS22: 937-945

74. Goedert JJ et al. (2007) Risk of germ cell tumors among men with HIV/acquired immunodeficiency syndrome. Cancer Epidemiol Biomarkers Prev 16: 1266-1269

75. Frisch M et al. for the AIDS-Cancer Match Registry Study Group (2001)Association of cancer with AIDS-related immunosuppression in adults. JAMA285: 1736-1745

76. Hausen HZ and Villiers ED (1994) Human papilloma viruses. Annu Rev Microbio/48: 427-447 
77. Leibovitch I and Goldwasser B (1994) The spectrum of acquired immunodeficiency syndrome-associated testicular disorders. Urology 44: 818-824

78. Hoffmann C (2007) Malignant lymphomas. In HIV Medicine 2007, 489-509 (Eds Hoffmann C. et al.) [http://www.hivmedicine.com/hivmedicine2007.pdf] (accessed 1 December 2008)

79. Burmer GC et al. (1993) Squamous cell carcinoma of the scrotum associated with human papillomaviruses. J Urol 149: 374-377

80. Parker DC. et al. (online 7 September 2006) Dermatologic diseases of the male genitalia: malignant. [http://www.emedicine.com/med/TOPIC3345.HTM]

81. Culkin DJ and Beer TM (2003) Advanced penile carcinoma. J Urol 170: 359-365

82. Sirera $\mathrm{G}$ et al. (2006) High prevalence of human papillomavirus infection in the anus, penis and mouth in HIV-positive men. AIDS 20: 1201-1204

83. Hadjivassiliou M et al. (2007) Human papillomavirus assay in genital warts-correlation with symptoms. Int J STD AIDS 18: 329-334

84. Kreuter A et al. for the German Competence Network HIV/AIDS (2008) Penile intraepithelial neoplasia is frequent in HIV-positive men with anal dysplasia. J Invest Dermatol 128: 23162324

85. Sumino $\mathrm{Y}$ et al. (2004) Urethral condyloma acuminata following urethral instrumentation in an elderly man. Int J Urol 11: 928-930

86. Nguyen P et al. (2002) Aggressive squamous cell carcinomas in persons infected with the human immunodeficiency virus. Arch Dermatol 138: 827-828

87. Manfredi R et al. (2006) Disseminated, lethal prostate cancer during human immunodeficiency virus infection presenting with non-specific features: open questions for urologists, oncologists, and infectious disease specialists.Cancer Detect Prev 30: 20-23

88. Silberstein J et al. (2008) HIV and prostate cancer: a systematic review of the literature. Prostate Cancer Prostatic Dis[doi:doi:10.1038/pcan.2008.44]

89. Vianna LE et al. (2006) Serum prostate-specific antigen levels in older men with or at risk of HIV infection. HIV Med 7: 471-476

90. Quatan N et al. (2005) Should HIV patients be considered a high risk group for the development of prostate cancer? Ann R Coll Surg Eng/ 87: 437-438

91. Levinson A et al. (2005) Approach to management of clinically localized prostate cancer in patients with human immunodeficiency virus. Urology 65: 91-94

92. Lallemand F et al. (2002) Sexual dysfunction in 156 ambulatory HIV-infected men receiving highly active antiretroviral therapy combinations with and without protease inhibitors. J Acquir Immune Defic Syndr 30: 187-190

93. Schrooten W et al. for the Eurosupport Study Group (2001) Sexual dysfunction associated with protease inhibitor containing highly active antiretroviral treatment. AIDS 15: 10191023

94. Sollima S et al. (2001) Protease inhibitors and erectile dysfunction. AIDS 15: 2331-2333

95. Lamba $\mathrm{H}$ et al. (2004) Antiretroviral therapy is associated with sexual dysfunction and with increased serum estradiol levels in men. Int J STD AIDS15: 234-237

96. Crum NF et al. (2005) A review of hypogonadism and erectile dysfunction and HIV infected men during the pre-and post HAART eras: diagnosis, pathogenesis, and management. AIDS Patient Care STDS 19: 655-671

97. Alciati A et al. (2007) Major depression-related immunological changes and combination antiretroviral therapy in HIVB-seropositive patients. Hum Psychopharmacol 22: 33-40

98. Fava M et al. (2006) Efficacy and safety of sildenafil in men with serotonergic antidepressant associated erectile dysfunction: results from a randomized, double blind placebo controlled trial. J Clin Psychiatry 67: 240-246

99. Ende AR et al. (2006) Erectile dysfunction in an urban HIV-positive population.AIDS Patient Care STDS 20: 75-78

100. Srinivas-Shankar U and Wu FCW (2006) Drug insight: testosterone preparations. Nat Clin Pract Urol 3: 653-665 
101. Karlovsky M et al. (2004) Increasing incidence and importance of HIV/AIDS and gonorrhea among men aged $>50$ in the US in the era of erectile dysfunction therapy. Scan J Urol Nephrol 38: 247-252

102. Benotsch EG et al. (2006) Substance use, medications for sexual facilitation, and sexual risk behavior among traveling men who have sex with men. Sex Transm Dis 33: 706-711

103. Nurnberg HG and Duttagupta S (2004) Economic analysis of sildenafil citrate (Viagra) add-on to treat erectile dysfunction associated with selective serotonin reuptake inhibitor use. Am J Ther 11: 9-12

104. Sadeghi-Nejad H et al. (2000) Erectile dysfunction in the HIV-positive male: a review of medical, legal and ethical considerations in the age of oral pharmacotherapy. Int J Impot Res 12 (Suppl 3): S49-S53

105. Sonnenberg-Schwan U et al. (2007) HIV and wish for parenthood. In HIV Medicine 2007, 685694 (Eds Hoffmann C. et al.) [http://www.hivmedicine.com/hivmedicine2007.pdf] (accessed 1 December 2008)

106. Semprini AE et al. (1992) Insemination of HIV-negative women with processed semen of HIVpositive partners. Lancet 340: 1317-1319

107. Garrido N et al. (2004) Report of the results of a 2 year programme of sperm wash and ICSI treatment for human immunodeficiency virus and hepatitis $\mathrm{C}$ virus serodiscordant couples. Hum Reprod 19: 2581-2586

108. Heylen R and Miller R (1997) Adverse effects and drug interactions of medications commonly used in the treatment of adult HIV-positive patients: part 2. Genitourin Med 73: 5-11

109. Tashima KT et al. (1997) Indinavir nephropathy. N Engl J Med 336: 138-139

110. Bruce RG et al. (1997) Urolithiasis associated with the protease inhibitor indinavir. Urology 50: 513-518

111. Daudon M et al. (1997) Urinary stones in HIV-1 positive patients treated with indinavir. Lancet 349: 1294-1295

112. Kalaitzis $C$ et al. (2007) Urological management of indinavir-associated acute renal failure in HIV-positive patients. Int Urol Nephrol 39: 743-746

113. Dieleman JP et al. (1999) Urological complaints in relation to indinavir plasma concentrations in HIV-infected patients. AIDS 13: 473-478

114. Collin F et al. (2007) Indinavir trough concentration as a determinant of early nephrolithiasis in HIV-1-infected adults. Ther Drug Monit 29: 164-170

115. Kohan AD et al. (1999) Indinavir urolithiasis: an emerging cause of renal colic in patients with human immunodeficiency virus. J Urol 161: 1765-1768

116. Meraviglia P et al. (2002) Risk factors for indinavir-related renal colic in HIV patients: predictive value of indinavir dose/body mass index. AIDS 16: 2089-2093

117. Nadler RB et al. (2003) The etiology of urolithiasis in HIV-infected patients. J Urol 169: 475477

118. Salahuddin S et al. (2001) Is indinavir crystalluria an indicator for indinavir stone formation? AIDS 15: 1079-1080

119. Wu DS and Stoller ML (2000) Indinavir urolithiasis. Curr Opin Urol 10: 557-561

120. Gentle DL et al. (1997) Protease inhibitor-induced urolithiasis. Urology 50: 508-511

121. Harris M (2008) Nephrotoxicity associated with antiretroviral therapy in HIV-infected patients. Expert Opin Drug Saf 7: 389-400

122. Rho M and Perazella MA (2007) Nephrotoxicity associated with antiretroviral therapy in HIVinfected patients. Curr Drug Saf 2: 147-154 
123. Weiss HA et al. (2000) Male circumcision and risk of HIV infection in sub-Saharan Africa: a systematic review and meta-analysis. Aids 14: 2361-2370

124. Patterson BK et al. (2002) Susceptibility to human immunodeficiency virus-1 infection of human foreskin and cervical tissue grown in explant culture. Am J Pathol 161: 867-873

125. Soilleux EJ and Coleman N (2004) Expression of DC-SIGN in human foreskin may facilitate sexual transmission of HIV. J Clin Pathol 57: 77-78

126. McCoombe SG and Short RV (2006) Potential HIV-1 target cells in the human penis. AIDS 20: 1491-1495

127. Fink AJ (1986) A possible explanation for heterosexual male infection with AIDS. N Engl J Med 315: 1167

128. Moses $S$ et al. (1999) Analysis of the scientific literature on male circumcision and risk for HIV infection. Int J STD AIDS 10: 626-628

129. Drain PK et al. (2006) Male circumcision, religion, and infectious diseases: an ecologic analysis of 118 developing countries. BMC Infect Dis 6: 172

130. Weiss HA et al. (2008) Male circumcision for HIV prevention: from evidence to action? AIDS 22: 567-574

131. Auvert B et al. (2005) Randomized, controlled intervention trial of male circumcision for reduction of HIV infection risk: the ANRS 1265 Trial. PLoS Med2: e298

132. Bailey RC et al. (2007) Male circumcision for HIV prevention in young men in Kisumu, Kenya: a randomised controlled trial. Lancet 369: 643-656

133. Gray RH et al. (2007) Male circumcision for HIV prevention in men in Rakai, Uganda: a randomised trial. Lancet 369: 657-666

134. Krieger JN and Heyns CF: Male circumcision and HIV/AIDS risk-analysis of the scientific evidence. Afr J Urol, in press 